\title{
Zika Virus and Glioblastomas: Can Zika Be an Effective Weapon to Eradicate Brain Cancer?
}

\author{
Md. Tanvir Kabir ${ }^{1}$, Md. Sahab Uddin ${ }^{2^{*}}$ \\ ${ }^{1}$ Department of Pharmacy, BRAC University, Dhaka, Bangladesh; \\ ${ }^{2}$ Department of Pharmacy, Southeast University, Dhaka, Bangladesh.
}

*Corresponding to: Md. Sahab Uddin, Department of Pharmacy, Southeast University, Dhaka, Bangladesh. Tel.: +880 1710220110; E-mail address: msu-neuropharma@hotmail.com, msu_ neuropharma@hotmail.com.

Zika virus (ZIKV) is a mosquito-borne flavivirus and a member of the virus family Flaviviridae ${ }^{[1]}$. ZIKV was first identified in monkeys in 1947, while a group of researchers were monitoring yellow fever in Uganda ${ }^{[2]}$. In Brazil, an association between Guillain-Barré syndrome and ZIKV infection was reported in July $2015^{[3]}$. WHO has established that congenital brain abnormalities such as microcephaly are the consequences of infection caused by ZIKV during pregnancy period. ZIKV is also a trigger of Guillain-Barré syndrome. Africa, the Pacific Islands, parts of the Caribbean, United States, Southeast Asia and Central and South America are the regions where the outbreaks of ZIKV have been observed ${ }^{[4]}$. There are a number of ongoing researches which are scrutinizing the connection between various neurological disorders and ZIKV.

The studies on recent outbreaks have discovered that this virus can cause brain defects in unborn children ${ }^{[5]}$. If a woman is infected with ZIKV during pregnancy, this can increase the chances of miscarriage and also can cause microcephaly (i.e. abnormally small heads) and other related neurological disorders. The virus exerts these types of effects by passing from blood into the brain. In the developing brains, the virus can severely infect and destroy stem cells ${ }^{[6]}$. Interestingly, this capability of infecting brain's stems cells might be a useful tool to fight fatal brain cancers triggered by mutated stem cells (Fig. 1).

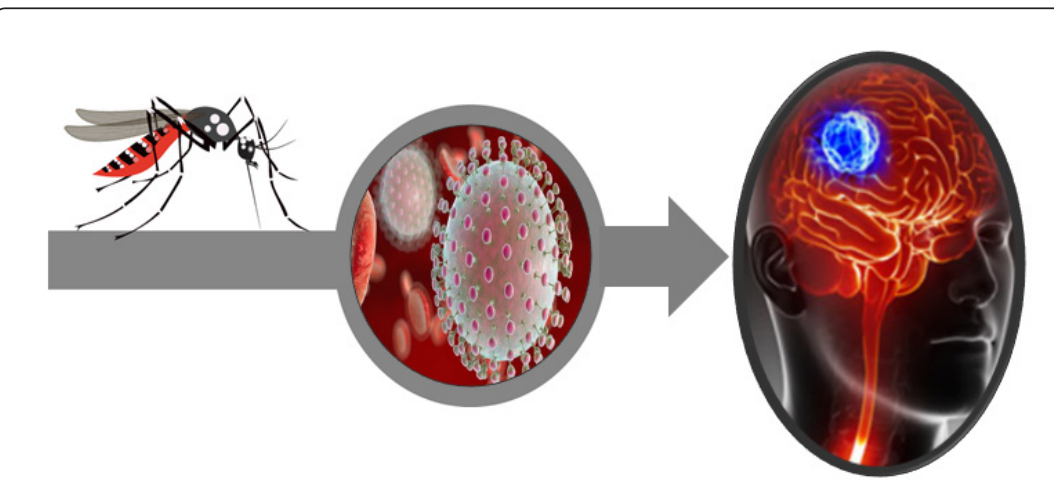

Copyright: ๑2017 Cain et al. This is an open access article distributed under the terms of the Creative Commons Attribution License, which permits unrestricted use, distribution, and reproduction in any medium, provided the original author and source are credited.

Fig. 1 ZIKV is causative for irresistible microcephaly could offer up a miraculous new treatment scheme for the glioblastomas. The denouements are auspicious, but extensive further studies are prerequisite for disputing copious interfering factors. 
Recently a study of Zhu et al., has been carried out to test the oncolytic effect of ZIKV on glioblastoma stem cells ${ }^{[7]}$. Glioblastomas start within the brain and is the most aggressive cancer ${ }^{[8]}$. Moreover, glioblastomas represent as many as $15 \%$ of brain tumors ${ }^{[9]}$. These tumors can either arise from normal brain cells or can develop from a previously existing low-grade astrocytoma. Still now, there is no specific treatment plan to prevent these deadly brain tumors and they are very difficult to treat as well. Normally, surgery is the available treatment followed by radiation therapy and chemotherapy. Forlornly, the usual survival rate is very low and the length of survival is normally 12 to 15 months. Moreover, only less than 3 to $5 \%$ of the patients survive more than 5 years ${ }^{[10]}$. As like in other healthy tissues, glioblastomas' growth and development are controlled by stem cells that can undergo proliferation and generate other tumor cells. These glioblastoma stem cells are notorious and very hard to destroy, since they can bypass the immune system of human body. Moreover, they are resistant to radiation and chemotherapy. Nevertheless, following surgical removal of the original tumor, it is crucial to destroy these stem cells to stop further recurring of new tumors.

Using viruses which will selectively target tumor cells can be one way to destroy the cancer stem cells. In fetus, ZIKV specifically can target neural stem and progenitor cells and can disturb the brain development ${ }^{[11]}$. However, in adults, the effects of the virus are less severe due the presence of comparatively fewer stem cells in adult brains.

The researchers injected ZIKV into the brain tumors of 18 mice and saltwater (i.e. used as a placebo) into the brain tumors of 15 mice. Subsequent observations and comparisons with the mice in which saltwater was administered revealed that following 2 weeks of ZIKV injection, the tumors of the mice got sufficiently smaller and eventually survived longer ${ }^{[12]}$. These results are certainly encouraging. In human beings, if ZIKVes are used, they need to be injected directly into the brains while performing the surgery to remove the primary tumor. On the other hand, if the virus is introduced through other body parts except brain, immune system of the patient's body can destroy the virus before reaching the brain ${ }^{[13]}$.

Although the injection of such insipid virus that causes damage to the human brain seems shocking, nonetheless its use in adults might be safer because ZIKV primary targets neuroprogenitor cells that are sporadic in the adult brain. Oppositely, these target cells are copiously found in the fetal brain. This phenomenon further explains severe brain damage due to the infection caused by the ZIKV before birth. However, in adults, such infections are much more natural and exert mild symptoms ${ }^{[14]}$

Furthermore, researchers discovered that ZIKV was also effective in destroying the cancer stem cells when exposed to the samples of human glioblastomas grown in a dish. On the other hand, when the researchers exposed this virus on normal and adult human brain cells free from cancer, they discovered that the virus did not infect this tissue and this finding further specifies the less severe effects exerted by the virus in adults ${ }^{[6]}$. Afterwards, the researchers experimented with the mice which were implanted with glioblastomas. Typically such types of mice die within a month, however the mice lived longer which were injected with ZIKV. Furthermore, researchers also found that 4 out of 9 mice were quiet alive at 2 months ${ }^{[6]}$.

Then, the researchers experimented with the less virulent (i.e. as compare to strains of the virus that are naturally occurring) Zika's mutant strain. This attenuated strain of the virus is much more sensitive to the immune response of the body. Moreover, this attenuated strain was also effective in specifically targeting and killing the glioblastoma stem cells and found to be even more effective when used as a combination therapy along with a chemotherapeutic agent such as temozolomide. Temozolomide is an alkylating agent that is used in the treatment of glioblastomas (i.e. as a first-line treatment), astrocytoma (i.e. as a second-line treatment) and some brain cancers ${ }^{[15,16]}$.

The researchers avow that this is the first step towards the safe and effective strains development of ZIKV that could turn into an essential tool in neuro-oncology and also can be used in the treatment of glioblastomas. But Tang et al., reported that ZIKV terminate and interrupt the growth of neural progenitor cells (NPC), which are accountable for the expansion of the nervous system ${ }^{[17]}$. In this study, the virus infected the mainstream of the NPC subsequently one-third death of the cells. In another study Souza et al., stated that ZIKV infection induces mitosis abnormalities and apoptotic cell death of human NPC ${ }^{[18]}$. Most of the existing studies of ZIKV against glioblastomas were conducted on rodent model however ZIKV is human virus not rodent virus. ZIKV comprises single-stranded positive sense ribonucleic acid (RNA) genome of about $11 \mathrm{~kb}^{[19]}$. But RNA virus is able to insert their genetic material into host chromosomes. Extensive preclinical, clinical studies and assessments of the ability of the strains to revert back to more virulent forms are required to address public health concerns. Furthermore, the safety issues for injected living virus according to regulatory bodies (FDA, MHRA, TGA) is also considered. In spite of these existing queries, the therapeutic potentiality of ZIKV suggests a dominant armament in the battle of glioblastomas. 


\section{ACKNOWLEDGEMENTS}

The authors wish to thank the anonymous reviewer(s)/editor(s) of this article for their constructive reviews.

\section{CONFLICTS OF INTEREST}

The authors proclaim no conflicts of interest.

\section{REFERENCES}

1. Malone RW, Homan J, Callahan MV, GlasspoolMalone J, Damodaran L, Schneider Ade B, Zimler R, Talton J, Cobb RR, Ruzic I, Smith-Gagen J, Janies D, Wilson J; Zika Response Working Group. Zika virus: medical countermeasure development challenges. PLoS Negl Trop Dis. 2016; 10(3): e0004530.

2. Sikka V, Chattu VK, Popli RK, Galwankar SC, Kelkar D, Sawicki SG, Stawicki SP, Papadimos TJ. The emergence of Zika virus as a global health security threat: a review and a consensus statement of the INDUSEM Joint Working Group (JWG). J Glob Infect Dis. 2016; 8(1): 3-15.

3. World Health Organization. Zika virus microcephaly and Guillain-Barré Syndrome [cited 2017 Sept 10]. Available from: http://www.salud. gob.ec/wp-content/uploads/2015/12/WHO-ZikaSituation-Report_19-02-2016.pdf.

4. World Health Organization. Zika causality statement [cited 2017 Sept 10]. Available from: http://www.who.int/emergencies/zika-virus/ causality/en/.

5. ScienceDaily. Zika virus could be used to treat brain cancer patients, study suggests [cited 2017 Sept 10]. Available from: https:// www.sciencedaily.com/releases/2017/ 09/ 170905093550.htm.

6. New Scientist. We may be able to use Zika virus to attack brain cancer cells [cited 2017 Sept 10]. Available from: https://www.newscientist.com/ article/2146356-we-may-be-able-to-use-zikavirus-to-attack-brain-cancer-cells/.

7. Zhu Z, Gorman MJ, McKenzie LD, Chai JN, Hubert CG, Prager BC, Fernandez E, Richner JM, Zhang R, Shan C, Wang XX, Shi PY, Diamond MS, Rich JN, Chheda MG. Zika virus has oncolytic activity against glioblastoma stem cells. J Exp Med. 2017; pii: jem.20171093. DOI: 10.1084/jem.20171093.

8. Bleeker FE, Molenaar RJ, Leenstra S. Recent advances in the molecular understanding of glioblastoma. J Neurooncol. 2012; 108(1):11-27.

9. Young RM, Jamshidi A, Davis G, Sherman JH. Current trends in the surgical management and treatment of adult glioblastoma. Ann Transl Med. 2015; 3(9): 121.

10. Gallego O. Nonsurgical treatment of recurrent glioblastoma. Cur Oncol. 2015;22(4):e273-81.

11. CBS News. Could Zika virus help battle deadly brain cancer? [cited 2017 Sept 10]. Available from: https://www.cbsnews.com/news/couldzika-virus-help-battle-deadly-brain-cancer/.

12. Washington University School of Medicine. Zika virus kills brain cancer stem cells [cited 2017 Sept 10]. Available from: https://medicine.wustl. edu/news/zika-virus-kills-brain-cancer-stemcells/.

13. Siteman Cancer Center. Zika virus kills brain cancer stem cells [cited 2017 Sept 10]. Available from: https://siteman.wustl.edu/zika-virus-killsbrain-cancer-stem-cells/.

14. SCI News. Zika virus kills glioblastoma stem cells, new research shows [cited 2017 Sept 10]. Available from: http://www.sci-news. $\mathrm{com} /$ medicine/zika-virus-glioblastoma-stemcells-05199.html.

15. Amran MS, Uddin MS. Pharmakon comprehensive pharmaceutical pharmacology. 1st ed. Dhaka: Krishnachura Prokashoni; 2014.

16. Newton HB. Novel chemotherapeutic agents for the treatment of brain cancer. Exp Opi Investigat Dru. 2000; 9(12): 2815-2829.

17. Tang H, Hammack C, Ogden SC, Wen Z, Qian X, Li Y, Yao B, Shin J, Zhang F, Lee EM, Christian KM, Didier RA, Jin P, Song H, Ming GL. Zika virus infects human cortical neural progenitors and attenuates their growth. Cell Stem Cell. 2016; 18(5): 587-590.

18. Souza BS, Sampaio GL, Pereira CS, Campos GS, Sardi SI, Freitas LA, Figueira CP, Paredes BD, Nonaka CK, Azevedo CM, Rocha VP, Bandeira AC, Mendez-Otero R, Dos Santos RR, Soares MB. Zika virus infection induces mitosis abnormalities and apoptotic cell death of human neural progenitor cells. Sci Rep. 2016; 6(39775): 1-13.

19. Gupta AK, Kaur K, Rajput A, Dhanda SK, Sehgal M, Khan MS, Monga I, Dar SA, Singh S, Nagpal G, Usmani SS, Thakur A, Kaur G, Sharma S, Bhardwaj A, Qureshi A, Raghava GP, Kumar M. ZikaVR: An integrated zika virus resource for genomics, proteomics, phylogenetic and therapeutic analysis. Sci Rep. 2016; 6: 32713. 